\title{
RESISTENCIA ANTIMICROBIANA: NUEVO ENFOQUE Y OPORTUNIDAD
}

\author{
ANTIMICROBIAL RESISTANCE: A NEW APPROACH AND OPPORTUNITY
}

\author{
Martin Yagui ${ }^{1,2, a}$
}

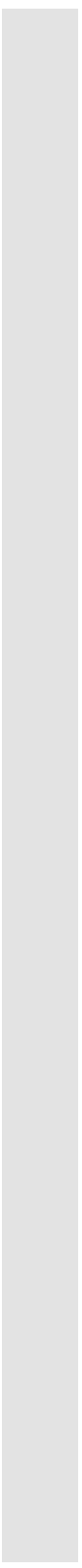

La resistencia a los antimicrobianos es un problema y amenaza mundial que tiene serias repercusiones en la salud humana, sanidad animal, vegetal y en el ambiente. Esta se puede generar bajo condiciones naturales o por el uso inadecuado y excesivo de los antimicrobianos.

La magnitud del problema en la salud humana ha sido caracterizada por la Organización Mundial de la Salud (OMS) a través del "Reporte global sobre la vigilancia de la resistencia antimicrobiana" del 2014, el cual resume lo informado por 129 estados miembros. Entre los principales hallazgos figuran los elevados porcentajes de resistencia a las cefalosporinas de tercera generación reportadas para la $E$. coli y K. pneumoniae, tanto para infecciones nosocomiales como para infecciones adquiridas en la comunidad. Se han reportado de igual forma, elevados niveles de resistencia para el $S$. aureus meticilino resistente en cinco continentes $(50 \%$ de resistencia o más) y una reducida susceptibilidad a la penicilina por parte del Streptococcus pneumoniae en todas las regiones de la OMS ${ }^{(1)}$.

Asimismo, se ha modelado el impacto económico de la resistencia a los antimicrobianos en un escenario de continuo incremento de la resistencia hacia el año 2050, estimándose la ocurrencia de diez millones de muertes anuales y una reducción del producto bruto interno mundial entre el $2 \%$ y el 3,5 \% ${ }^{(2)}$.

En este contexto, la Revista Peruana de Medicina Experimental y Salud Pública ha dedicado este número a la resistencia a los antimicrobianos, con la finalidad de resaltar este problema, hacerlo visible para los tomadores de decisiones y contribuir en la concientización de la comunidad sanitaria nacional.

El primer artículo del simposio se denomina «Enfoque de Una Salud en las acciones para enfrentar la resistencia a los antimicrobianos desde una óptica latinoamericana». Los autores explican en profundidad el enfoque de Una Salud resaltando algunas particularidades en el contexto latinoamericano, describen la respuesta mundial desde las políticas de salud internacionales, expresadas en el Plan de Acción Mundial sobre la Resistencia a los Antimicrobianos bajo el liderazgo de la OMS, la Organización para la Agricultura y la Alimentación (FAO) y la Organización Mundial de la Sanidad Animal (OIE); describen algunas estrategias de respuesta bajo el enfoque de Una Salud como una respuesta articulada desde la vigilancia, la detención del uso de antibióticos en animales sanos y la publicación de una lista de antimicrobianos de importancia crítica para la medicina humana para promover el uso prudente de dichos fármacos y enlentecer el desarrollo de resistencias. Finalmente concluyen el artículo resaltando la falta de conocimiento sobre la selección y propagación de organismos resistentes en el medio ambiente, como riesgo para la salud humana y animal ${ }^{(3)}$.

El segundo artículo del simposio se denomina "Gestión sanitaria y resistencia a los antimicrobianos en animales de producción”. Los autores describen los riesgos de generación de bacterias resistentes en el ciclo de la producción primaria animal en granja, mencionando que además del uso terapéutico de los antibióticos en la producción animal, también han sido aplicados con fines profilácticos y como promotores del crecimiento, siendo mayormente administrados a través de los alimentos. Describen las principales rutas de diseminación de bacterias resistentes procedentes de la producción animal hacia poblaciones humanas, entre ellas el consumo de alimentos de origen animal, el contacto directo con animales de granja y la contaminación ambiental y del medio acuático por medio de desechos de producción animal. Presentan diversas acciones preventivas en el marco de una gestión de la

Instituto Nacional de Salud. Lima, Perú.

Universidad Nacional Mayor de San Marcos. Lima, Perú

Editor invitado, médico especialista en patología clínica.

Recibido: 16/03/2018 Aprobado: 19/03/2018 En línea: 05/04/2018

Citar como: Yagui M. Resistencia antimicrobiana: nuevo enfoque y oportunidad. Rev Peru Med Exp Salud Publica. 2018;35(1):7-8. doi:10.17843/rpmesp.2018.351.3594 
sanidad animal, como las buenas prácticas de producción animal, aplicación de medidas de bioseguridad, entre otras. Finalmente, presentan algunas experiencias en el control del uso de antibióticos y de resistencia antimicrobiana en la producción animal ${ }^{(4)}$.

El tercer artículo del simposio se denomina "Tuberculosis multidrogo resistente en la era final de la tuberculosis". Los autores describen prolijamente las diferentes iniciativas implementadas para enfrentar a la tuberculosis (TB) multidrogo resistente (MDR) en las últimas tres décadas. Describen los avances para el diagnóstico y tratamiento de la TB resistente. Plantean que teniendo en cuenta las tendencias epidemiológicas a largo plazo, los avances en el diagnóstico y tratamiento, junto con los recursos del Fondo Mundial y otros donantes importantes, podemos estar a punto de acelerar la disminución de la morbilidad y mortalidad por TB MDR. Asimismo, formulan la necesidad de una mayor voluntad política para implementar estos avances enérgicamente, la necesidad de un mayor apoyo para la ciencia a fin de generar los avances del mañana para acelerar estas tendencias dado que el financiamiento para la investigación sobre la tuberculosis se ha estancado ${ }^{(5)}$.
El cuartoyúltimo artículo del simposio se denomina "Resistencia a antifúngicos". Los autores realizan una descripción de la importancia y epidemiología de las infecciones fúngicas, resaltando el incremento de su frecuencia y mortalidad atribuible. Posteriormente, describen las candidemias tanto albicans como las no albicans, remarcando el cambio de patrón etiológico de candidemias, observándose un incremento de la Candida no albicans, generando dificultades terapéuticas por los nuevos patrones de sensibilidad a antifúngicos. En último lugar, concluyen que la obtención de un diagnóstico precoz, la caracterización de las especies de candida y la detección de la resistencia a antifúngicos constituyen las herramientas básicas para el control de esta micosis invasora ${ }^{(6)}$.

Finalmente respondiendo al compromiso internacional para enfrentar la resistencia a los antimicrobianos, el Perú ha desarrollado el proyecto de plan nacional para enfrentar la resistencia a los antimicrobianos, bajo los lineamientos del Plan de Acción Mundial de la OMS. Este plan ha sido elaborado con participación multisectorial representativa de la salud humana, salud animal y sector fitosanitario, quedando pendiente su aprobación mediante Decreto Supremo.

\section{REFERENCIAS BIBLIOGRÁFICAS}

1. World Health Organization. Antimicrobial resistance: global report on surveillance [Internet]. Geneva: WHO; 2014 [citado el 1 de marzo de 2018]. Disponible en: http://www.who.int/drugresistance/ documents/surveillancereport/en/.

2. O'Neill J. Antimicrobial Resistance: Tackling a crisis for the health and wealth of nations [Internet]. London: Review on Antimicrobial Resistance; 2014 [citado el 1 de marzo de 2018].
Disponible en: https://amr-review. org/sites/default/files/AMR\%20Review\%20Paper\%20-\%20Tackling\%20 a\% 20 crisis $\% 20$ for $\% 20$ the $\% 20$ health\%20and\%20wealth\%20of\%20nations_1.pdf.

3. Ramón-Pardo P, Sati H, Galas M. Enfoque de UNA SALUD en las acciones para enfrentar la resistencia a los antimicrobianos desde una óptica latinoamericana. Rev Peru Med Exp Salud Publica. 2018;35(1):103-9.
4. Gatica M, Rojas H. Gestión sanitaria y Resistencia a los antimicrobianos en animales de producción. Rev Peru Med Exp Salud Publica. 2018;35(1):118-25.

5. Cegielski P, Jaramillo E. Tuberculosis multidrogo resistente en la era final de la tuberculosis. Rev Peru Med Exp Salud Publica. 2018;35(1):110-7.

6. Zurita S. Resistencia a antifúngicos. Rev Peru Med Exp Salud Publica. 2018;35(1):126-31.

\section{Nuestros artículos se encuentran indizados en:}

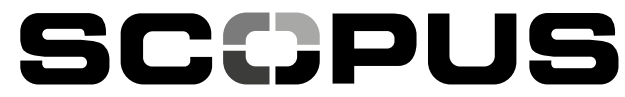

wWw.scopus.com 